\title{
Calculation of Energy Losses in Trolleybus Traction Network by Instant Equivalent Circuits Modeling
}

\author{
Spiridonov E. A. \\ Mechatronics and Automation Faculty \\ Novosibirsk State Technical University \\ Novosibirsk, Russia \\ spiridonov@corp.nstu.ru
}

\author{
Yaroslavtsev M. V. \\ Mechatronics and Automation Faculty \\ Novosibirsk State Technical University \\ Novosibirsk, Russia \\ yaroslavcev@corp.nstu.ru
}

\begin{abstract}
A typical approach to calculation of energy losses in traction circuits of electrified transport is compared to a proposed method of traction network electrical parameters calculation. The method is based on probabilistic experiments which include generation instant equivalent circuits of traction network and their calculation. The initial data for instant circuit generation were obtained experimentally for one of the trolleybus routes in Novosibirsk. A comparison of the traditional analytical approach and the proposed method of energy loss calculation based on a large amount of experimental data has been performed. Comparison results show that both methods give close power loss values. The proposed computational method may be used in power supply system calculations for its higher flexibility allowing accounting a high number of peculiarities and factors influencing the electric supply systems.
\end{abstract}

Keywords - Traction network, Trolleybus, Energy losses, Instantaneous Equivalent Circuit, Current distribution, DC electric traction

\section{INTRODUCTION}

Calculation of energy transmitted through feeders and a contact wire losses is usually performed as a part of designing electrical power supply systems for electrified transport. At present, following the development of energy-saving technologies, the problem of increasing the accuracy of loss calculation and developing new loss calculation methods becomes urgent. The increase in the accuracy of electrical calculations is necessary to compare the various technical solutions and to perform their technical and economic analysis as in [1-6].

Analytical methods of finding the current distribution in the traction network and the power, consumed by the trains [7, 8 ], use a number of assumptions and simplifications that lead to a calculation error of up to $10-20 \%$. For example, the contact networks of both paths are considered connected in parallel, the resistance of the supply lines is not taken into account, deviations of the actual train driving modes are not taken into account, the dependence of the train current on its speed is considered unchanged. Such simplifications are necessary to reduce the volume of calculations when performing them manually. The complexity of calculating power supply schemes is explained by a number of reasons that can be combined into two main groups:
1. Changes in the number of trains and the mutual arrangement of trains relative to each other and substations, which:

- Change the topology of the equivalent circuits;

- Change the resistance values of the traction network between the machines.

2. The presence of a number of nonlinearities in the properties of the elements of the circuits for replacing traction networks:

- Semiconductor devices in rectifier units at traction substations are unable to pass current in the opposite direction;

- The characteristics of the rolling stock depend on the voltage on its current collector. Although at modern impulse traction drives, which are used in urban transit, the traction motor current is the input value of the control system, representation of the traction drive as constant current source for long (more than a few seconds) time intervals is incorrect. When the voltage level in the traction network fluctuates, drivers change the setting of the traction drive current to ensure the realization of the desired acceleration. Therefore it is more correct to consider trolleybuses and trams as power than current consumers. As the results of experimental studies have shown, drivers rarely implement driving cycles in which the entire possible power of a traction drive is fully utilized.

- Impulse traction drives, having the ability to carry out rheostat and recuperative braking, are able to redistribute the braking power between the traction network and braking rheostats. Thus, in one mode of train movement, the power given to them will depend on the power of other consumers (such as trains, energy storages, inverters), which are electrically connected with the train in a braking mode.

Although the known methods of calculation allow us to select the substation power and the location of the substations quite accurately for practical purposes, there are a number of tasks required for a higher accuracy of calculation. At present, the development of computer technology makes it possible to perform a precise calculation of the current distribution in the traction network in a short time. Increasing the accuracy of current and power loss calculation will allow one to:

This work was done under financial support from RFBR № 16.08.00656. 
- Increase the accuracy of design of the power supply system; obtain a possibility of sufficiently precise comparison of the different operating modes of traction networks;

- develop measures to save energy and improve the energy efficiency of electric transport;

- propose solutions to increase the efficiency of regenerative braking energy application;

- select locations of energy storage devices and the effect of their introduction;

- improve methods for selecting settings in short-circuit protection systems;

- more accurately determine the boundaries of the anode and cathode zones for rail networks at rail transit.

Therefore the problem of increasing the accuracy of power supply system loss calculation provokes a great interest [9$12]$.

\section{Standard Analytical Method of EnERGy Loss CALCUlation Using AVERAGE CURRENT VAlues}

The standard method of energy loss calculation using mean and effective values of electric variables is described in $[7,8]$. The analytical method of calculations is based on the assumption that instant values of the traction current are random. The integral numeric characteristics of the train current are the average train current $\left(\mathrm{I}_{0}\right)$ and the effective (or RMS) train current $\left(I_{e}\right)$. Typically, the value of the average train current is used to estimate the traction energy consumption, while the value of the effective train current is used to estimate the power losses in the elements of the traction power supply system because it measures the spread of the instant values relative to the average.

Special attention must be paid to the determination of mean and effective currents. The mean train current, as an integral value characterizing the traction power consumption, is usually calculated from a given value of the specific energy consumption $\mathrm{A}, \mathrm{kW}$ per ton-km. However, this method contains a serious assumption of the average voltage in the traction network constancy (1):

$$
I_{0}=\frac{A V_{a}}{U_{T N} L}, \mathrm{~A}
$$

where $\mathrm{V}_{\mathrm{a}}$ is the average train velocity,

$\mathrm{U}_{\mathrm{TN}}$ stands for traction network nominal voltage,

$\mathrm{L}$ is the length of traction network section.

In the practice of traction calculations, the method of base currents may be used to determine the average current of a train. It is based on of average current values for different types of rolling stock obtained under certain basic conditions. There are adjusted to real conditions using coefficients that take into account profile of the path and span length, weather conditions, etc.

This method cannot be used for a more modern rolling stock, because there is no data on the values of its base currents. In such cases the average train current may be obtained by experimental investigations.

Power and energy losses are usually calculated using effective current of the train. The effective current value is usually determined from the average current and efficiency factor $k_{\mathrm{e}}$ of the train current. The efficiency factor in turn is determined either by experimentally obtained nomograms or by means of empirical expression (2) depending on the discontinuity factor of train current $\alpha$ (fig. 1).

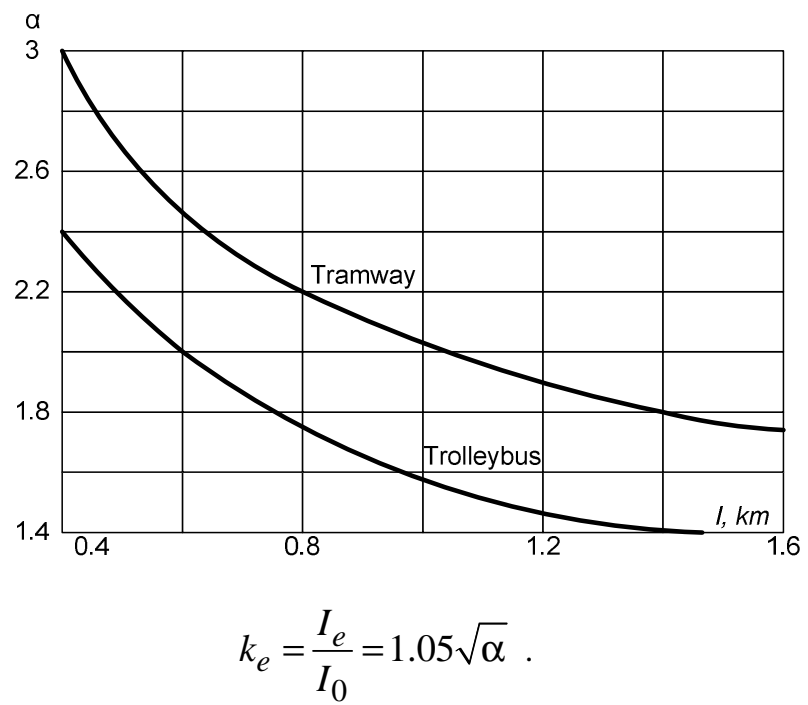

Fig. 1. Discontinuity factor $\alpha$ of train currents for trams and trolleybuses.

The mean current of a feeder line for a rolling stock of the same type is defined as the algebraic sum of the average currents of the trains on the traction network section. The average current of the substation is equal to the sum of the average feeder currents. The value of feeder line effective current $\mathrm{I}_{\mathrm{fe}}$ is determined by the sum of variances (3):

$$
I_{f e}=I_{0}^{2} n^{2}\left(1+\frac{k_{e}^{2}-1}{n}\right), \mathrm{A}
$$

where $\mathrm{n}$ is the number of trains.

The main purpose of electrical calculations of the traction power supply system is to determine the values of the voltage drop and power losses and compare them with the standardized indicators. The analytical method of calculation is widely used in practice. In the analytical method, the following assumptions were made for the derivation of generalized computational formulas:

- The number of trains on section $\mathrm{n}$ is a random variable determined by its mean value of $n_{c}$ and effective (RMS) value $\mathrm{n}_{\mathrm{e}}$;

- The train currents are independent random variables determined by the mean $\mathrm{I}_{0}$ and effective (RMS) $\mathrm{I}_{\mathrm{e}}$ values; 
- Trains can occupy any position relative to each other and consume any of the possible currents on the section. For a one-side powered section, the average $\mathrm{I}_{\mathrm{f} 0}$ and effective $\mathrm{I}_{\mathrm{fe}}$ line currents are determined by expressions (4):

$$
\begin{aligned}
& I_{f 0}=n_{0} I_{0}, A \\
& I_{f e}=n_{0} I_{e}^{2}+\left(n_{e}^{2}-n_{0}\right) I_{0}^{2}, A
\end{aligned}
$$

where $\mathrm{n}_{0}$ and $\mathrm{n}_{\mathrm{e}}$ are mean and RMS (so-called effective) numbers of trains in the section of traction network. They can be found using the daily load graph, showing dependence of the train number on time. The average voltage loss can be determined from expression (5):

$$
\Delta U=\frac{n_{0} I_{0} r l}{3}\left(1+\frac{1}{2 n_{0}}\right), \mathrm{V} .
$$

The average voltage drop for the consuming current train (6) is calculated as:

$$
\Delta U_{\text {Current }}=\frac{n_{0} I_{0} r l}{3}\left(1+\frac{1,5 \alpha-1}{n_{0}}\right), \mathrm{V}
$$

The average power losses in a section are determined by expression (7):

$$
\Delta P=\frac{n_{0} I_{e}^{2} r l}{2}+\frac{\left(n_{e}^{2}-n_{0}\right) I_{0}^{2} r l}{3}, \mathrm{~kW}
$$

For the sections with two-side power supply, similar values are calculated by formulas $(8)-(10)$ :

$$
\begin{gathered}
I_{f 0}=\frac{n_{0} I_{0}}{2}, \mathrm{~A} \\
I_{f e}=\frac{n_{0} I_{e}^{2}}{3}+\frac{\left(n_{e}^{2}-n_{0}\right) I_{0}^{2}}{4}, \mathrm{~A} \\
\Delta P=\frac{n_{0} I_{e}^{2} r l}{6}+\frac{\left(n_{e}^{2}-n_{0}\right) I_{0}^{2} r l}{12}, \mathrm{~kW}
\end{gathered}
$$

\section{Alternative Method of ENERGy LOSS CALCULATION BY INSTANT EQUIVALENT CIRCUITS MODELING}

To increase the accuracy of the power supply system calculation, an alternative method was proposed [13]. The process can be divided into two parts:

- Creation of instant equivalent circuits of the traction network;
- Calculation of instant equivalent circuits of the traction network.

\section{A. Creation of Instant Equivalent Circuits of the Traction Network}

To correctly evaluate such parameters of the traction network operation as the average power supplied by the substation and the average and effective feeder currents, it is necessary to have a sufficiently large set of initial instant equivalent circuits.

Instant equivalent schemes should represent the possible modes of operation of the traction network so that the probability of occurring the $i$-th mode corresponds to the proportion of the instant equivalent schemes, simulating it in the exploring array.

To obtain instant schemes of substitution of the traction network, it is suggested to use the method of probabilistic experiment. In this method, the random sections of the timetable graph are modeled by the selection of random points from previously obtained in some way the motion curves that define pairs of train coordinate - power consumption values. For a given number of trains on a section, such pairs of values are randomly selected without modeling train movements. The initial dependencies of the vehicle power on its coordinate can be obtained by an experimental study of traffic regimes or on the basis of known distribution laws [14]. The advantage of this method is the ease of implementation. Its disadvantage is the inability to take into account the mutual influence of train movement on each other, for example, the coordinates of the two following trains in one direction may coincide, which is impossible.

The result presents information about the coordinates of trains located on the traction network section and the power consumed or supplied by their traction drives. In the braking mode, the maximum power that the train is able to supply under the sufficient power of other energy consumers is set. In addition, before the calculation begins, the location of the traction substations is assigned, as well as the resistance of the contact and rail networks.

An example of the placement of trains on the traction network section represented by a sketch of the traction network section (a), and the corresponding instant equivalent circuit (b) is shown in Fig. 2.

\section{B. Calculation of Instant Equivalent Traction Network Circuits}

Calculation of instant equivalent traction network circuits is made by progressive approximation. It allows calculation of lines with separate and parallel supply and with diverse quantity of voltage sources modeling traction substations. An algorithm in MATLAB language performing calculation of instantaneous circuits had been proposed and realized by the authors. MATLAB was chosen to perform calculations as it can use effective ways of storing matrix data and solving matrix equations. The algorithm consists of following operations:

1. Loading of instantaneous equivalent traction network circuit parameters which had been previously obtained by any 
of available ways. Circuits may differ by quantity of trains, their coordinates and their consumed or returned power for the same section of traction network.

2. Sorting of objects at the traction network section by their coordinate. The object can be a train, a substation or parallel connection point. Sorting is necessary for the correct evaluation of catenary resistance.
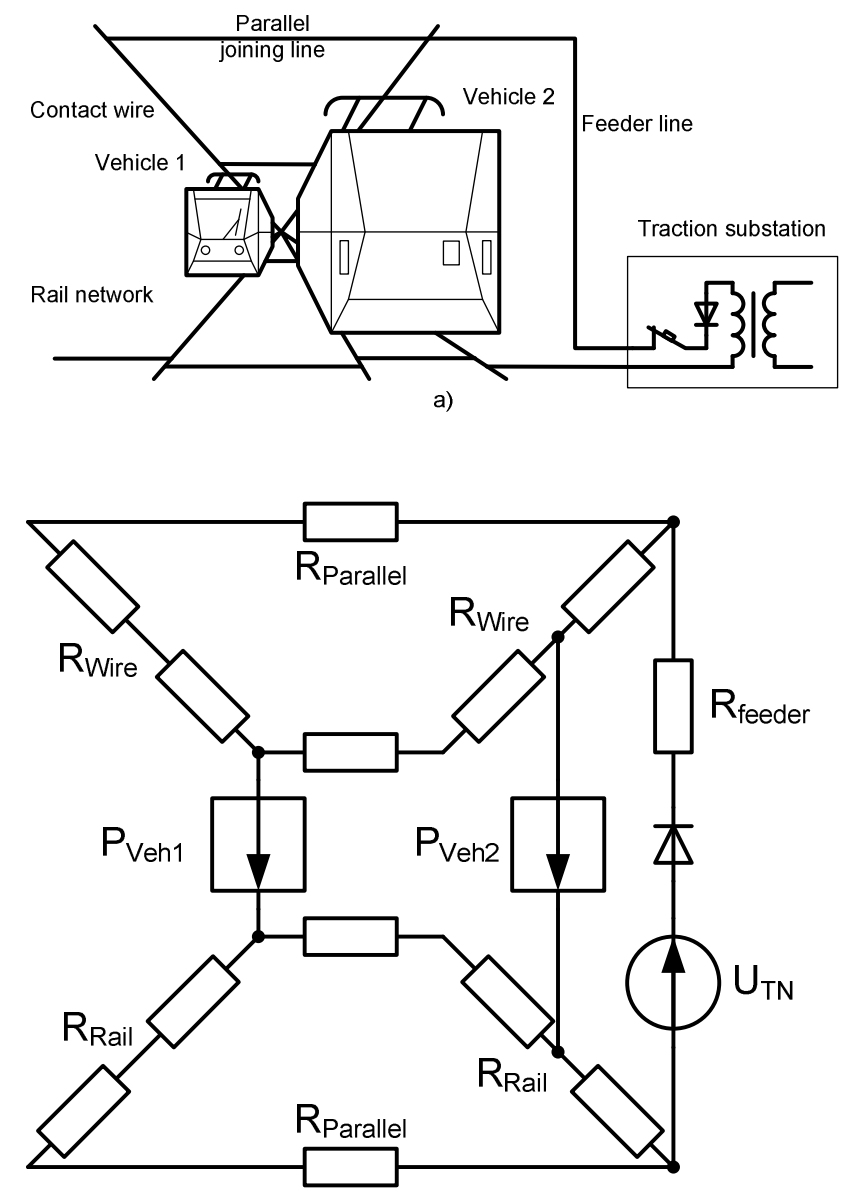

Fig. 2. Generation of instant equivalent circuits: (a) - sketch of the traction network section, (b) - corresponding instant equivalent circuit.

3. Formation of equation system which describes instantaneous circuit. Circuit is calculated by the node voltages method allowing approximation of current values only with constant conductance matrix $Y$. As the first assumption train power is set equal to 0 , and current vector $\mathbf{J}$ represents only short-circuit currents of traction substations (11). So for the i-th substation:

$$
\begin{aligned}
J_{4 i+1} & =\frac{U_{O C i}}{R_{i}} ; \\
J_{4 i+3} & =-\frac{U_{O C i}}{R_{i}} .
\end{aligned}
$$

where $\mathrm{U}_{\mathrm{OCi}}$ is $i$-th substation open-circuit voltage; $R_{i}$ is ${ }_{i}$-th substation resistance.

4. Solving the equation system. In the matrix notation node, voltages vector $\Phi$ is calculated by formula (12).

$$
\Phi=Y / J^{\prime}
$$

5. Current vector correction. At this stage, train powers are corrected first. At the each iteration, the effective power of each train is increased by the half of difference between its effective and specified by instantaneous circuit parameters values. Currents which are consumed or returned by trains are found by division of train power by voltage at its current collector. If this voltage had exceeded feasible constraint, the train power is limited. So for the i-th train at the II lane at the q-th iteration (fig. 3) the current is calculated by equations (13):

$$
\begin{aligned}
& P_{i q}=\left[\begin{array}{l}
P_{i 0}+\frac{P_{i 0}}{q+1}, \text { if } \varphi_{4 i+3}-\varphi_{4 i+1}<U_{\max } \\
P_{i 0}, i f \varphi_{4 i+3}-\varphi_{4 i+1}>U_{\max }
\end{array}\right. \\
& J_{4 i+1}=\frac{P_{i q}}{\varphi_{4 i+3}-\varphi_{4 i+1}} ; \\
& J_{4 i+3}=\frac{-P_{i q}}{\varphi_{4 i+3}-\varphi_{4 i+1}} .
\end{aligned}
$$

where $\mathrm{P}_{\mathrm{i}}$ is the average power of $i$-th substation, $\mathrm{kW}$; $\varphi$ are node voltages, $\mathrm{V}$;

$\mathrm{U}_{\max }$ is feasible network voltage constraint, $\mathrm{V}$.

If the voltage at traction substation output line exceeds its open-circuit voltage, the latter is increased to obtain zero current. Thus blocking of diodes in rectifier units is modeled to prevent reverse currents.

Stages 4 and 5 are repeated to obtain required solution accuracy. The accuracy is evaluated as absolute difference between node potentials which have been calculated at current and previous iterations.

6. Traction substation current and power calculation. Average and effective currents of substations may be found after multiple instantaneous circuits have been calculated. Specific energy consumption $\mathrm{E}$ at traction substation buses may also be found (14):

$$
E=\frac{\sum P_{i}}{1000 m n V}, \mathrm{~W} \cdot \mathrm{h} / \mathrm{t} \cdot \mathrm{km},
$$

where $\mathrm{n}$ is the quantity of trains at the traction network section;

$\mathrm{m}$ is the average weight of trains, metric tons;

$\mathrm{V}$ is the mean velocity at the traction network section, $\mathrm{km} / \mathrm{h}$. 


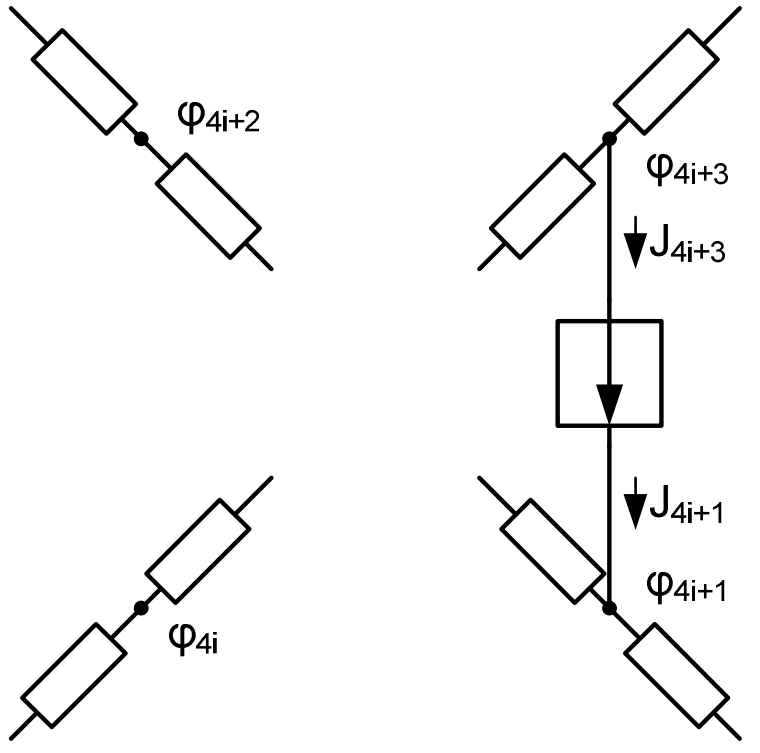

Fig. 3. Fragment of equivalent circuit for the i-th train

\section{A COMPARISON OF LOSS CALCULATION METHODS}

To compare the described methods, a daily load graph for the trolleybus traction network section, which is shown in fig. 4, was applied.

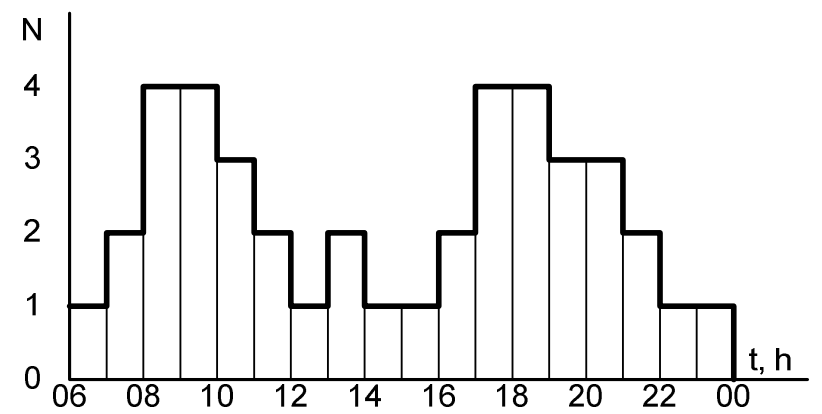

Fig. 4. Daily load graph. $\mathrm{N}$ is the number of trolleybuses on the traction network section.
$30 \mathrm{~kW}$ are installed on trolleybuses and substantially affect the current distribution in winter. Sections with one- and two-side power supply were tested. Two distributions of power consumed by trolleybuses were taken to calculate traction currents: with recuperative braking allowed and prohibited.

The mean and RMS currents which were used to perform analytical calculation of power losses are shown in Table 1. The currents Ii were calculated from the massive of instant power consumption values $\mathrm{Pi}$ by the equation (15) from the data for creation of instant equivalent circuits. Then an array of these currents was used to calculate average and RMS (effective) values.

$$
I_{i}=\frac{P_{i}}{U_{T N}}, \text { A. }
$$

TABLE I. MEAN AND EFFECTIVE CURRENTS OF TROLLEYBUSES IN DIFFERENT CONDITIONS

\begin{tabular}{|l|c|c|}
\hline $\begin{array}{l}\text { Conditions of } \\
\text { exploitation }\end{array}$ & Average current $\mathbf{I}_{\mathbf{0}}[\mathbf{A}]$ & $\begin{array}{l}\text { Effective current } \mathbf{I}_{\mathbf{e}} \\
{[\mathbf{A}]}\end{array}$ \\
\hline $\begin{array}{l}\text { Summer, without } \\
\text { recuperative braking }\end{array}$ & 41.3 & 82.2 \\
\hline $\begin{array}{l}\text { Summer, with } \\
\text { recuperative braking }\end{array}$ & 33.1 & 86.4 \\
\hline $\begin{array}{l}\text { Winter (30 kW } \\
\text { heaters) without } \\
\text { recuperative braking }\end{array}$ & 90.0 & 117.7 \\
\hline $\begin{array}{l}\text { Winter (30 kW } \\
\text { heaters) with } \\
\text { recuperative braking }\end{array}$ & 87.6 & 118.6 \\
\hline
\end{tabular}

The power losses in catenary lines are shown in table 2 . During modeling, 20,000 instant equivalent circuits were created and calculated for each set of conditions. Such high number of random combinations ensures a $\delta \mathrm{P}=0.8 \%$ accuracy of calculated power loss values, found by equation (16):

TABLE I.

$$
\delta P=100 \% \cdot \frac{\sigma_{P}}{\Delta \bar{P} \sqrt{N}}, \%
$$

\begin{tabular}{|c|c|c|c|c|c|}
\hline Conditions of exploitation & $\begin{array}{l}\text { Power supply of } \\
\text { contact sections }\end{array}$ & $\begin{array}{l}\text { Contact section } \\
\text { length }[\mathrm{km}]\end{array}$ & $\begin{array}{l}\text { Losses by analytical } \\
\text { method }[\mathrm{kW}]\end{array}$ & $\begin{array}{l}\text { Losses by } \\
\text { modeling }[\mathrm{kW}]\end{array}$ & $\begin{array}{l}\text { Difference } \\
{[\%]}\end{array}$ \\
\hline Summer, without recuperative braking & 1-side & 1 & 4.236 & 4.148 & -2.07 \\
\hline Summer, with recuperative braking & 1-side & 1 & 4.220 & 3.813 & -9.64 \\
\hline Winter without recuperative braking & 1-side & 1 & 11.416 & 10.962 & -3.98 \\
\hline Winter with recuperative braking & 1-side & 1 & 11.264 & 10.743 & -4.63 \\
\hline Summer, without recuperative braking & 2-side & 1 & 1.328 & 1.267 & -4.57 \\
\hline Summer, with recuperative braking & 2-side & 1 & 1.352 & 1.428 & 5.62 \\
\hline Winter without recuperative braking & 2-side & 1 & 3.406 & 3.318 & -2.60 \\
\hline Winter with recuperative braking & 2-side & 1 & 3.376 & 3.341 & -1.05 \\
\hline Summer, without recuperative braking & 2-side & 2 & 2.656 & 2.787 & 4.94 \\
\hline Summer, with recuperative braking & 2-side & 2 & 2.706 & 2.890 & 6.81 \\
\hline Winter without recuperative braking & 2-side & 2 & 6.812 & 7.400 & 8.63 \\
\hline Winter with recuperative braking & 2-side & 2 & 6.752 & 7.377 & 9.26 \\
\hline
\end{tabular}

Power losses for different exploitation conditions were calculated. In Siberian conditions heaters with total power of where $\delta \mathrm{P}$ is power loss calculation relative accuracy, $\sigma_{\mathrm{P}}$ is dispersion of power loss values, 
$\Delta \bar{P}$ is the average power loss value,

$\mathrm{N}=20,000$ is a number of trials.

As it can be seen from table 2, both analytical and modeling methods of power loss calculation give similar results. The difference between two methods does not exceed $10 \%$. The proposed computational method may be used in power supply system calculations for its higher flexibility allowing accounting a high number of peculiarities and factors influencing the electric supply systems. Finding the causes of difference between data achieved by two approaches and experimental verification of obtained results are the next closest problems in developing the proposed traction network calculation method.

\section{SUMMARY}

A method of traction network electrical parameters calculation with high accuracy was proposed. The method is based on probabilistic experiments which include generation instant equivalent circuits of the traction network and their calculation. The initial data for instant circuit generation were obtained experimentally.

A comparison of the traditional analytical approach and the proposed method of energy loss calculation based on a large amount of experimental data has been performed. Comparison results show that both methods give close power loss values with the difference not exceeding $10 \%$. The proposed computational method may be used in power supply system calculations for its higher flexibility allowing accounting a high number of peculiarities and factors influencing the electric supply systems. Finding the causes of difference between data, achieved by two approaches and experimental verification of obtained results, are the next closest problems in developing the proposed traction network calculation method.

\section{References}

[1] W. Jarzyna, D. Zieliński, P. Hołyszko, "Battery-supported trolleybus traction network - a component of the municipal smart grid", Environmental Engineering V Proceedings of the 5th National Congress of Environmental Engineering, pp. 287-292, 2017.
[2] Y. Liao, Z. Liu, G. Zhng, C. Xiang, "Vehicle-Grid System Modeling and Stability Analysis with Forbidden Region-Based Criterion", IEEE Transactions on Power Electronics, vol. 32, iss. 5, pp. 3499-3512, 2017.

[3] I. Maghsoud, A. Ghassemi, S. Farshad, S. S. Fazel, "Current balancing, reactive power and harmonic compensation using a traction power conditioner on electrified railway system", 21st Iranian Conference on Electrical Engineering [ICEE 2013], article 65998822013, 2013.

[4] T. Zhao, M. Wu, "Electric power characteristics of all-parallel at traction power supply system", Proceedings 2011 International Conference on Transportation, Mechanical, and Electrical Engineering [TMEE 2011], article 6199346, pp. 895-898, 2011.

[5] X.-H. Zhang, S.-Q. Wu, "Discussion and analysis of the metro environment control system using vehicle regenerative braking energy in cold region", Journal of Railway Engineering Society, vol. 33, iss. 2, pp. 91-95, 2016.

[6] T. Li, M. Wu, F. He, K. Song, "Calculations of leakage impedance of rail to earth in ballastless track by finite element method", Lecture Notes in Electrical Engineering, vol. 288, iss. 2, pp. 223-232, 2014.

[7] V. V. Shevchenko, N. V. Arzamaszev, N. S. Bodruhina, "Elektroshabzhenie nazemnogo gorodskogo transporta" ["Power supply of city surface transit"], Transport, Moscow, 1987.

[8] V. I. Sopov, Y. A. Prokushev, "Electrosnabzhenie elektricheskogo transporta" ["Power supply of electric transport"], Novosibirsk State Technical University, Novosibirsk, 2006.

[9] W. Liu, Q. Li, B. Tang, M. Chen, "Probabilistic load flow for urban rail traction power supply based on Monte Carlo simulation", Journal of Southwest Jiaotong University, vol. 45, iss. 4, pp. 561-567, 2010.

[10] M. Wu, "Uniform chain circuit model for traction networks of electric railways", Proc. of the Chinese Society of Electrical Engineering, vol. 30 , iss. 28 , pp. $52-58,2010$.

[11] Z. Jia, Z. Yang, F. Lin, X. Fang, "Dynamic simulation of the DC traction power system considering energy storage devices", IEEE Transportation Electrification Conference and Expo [ITEC Asia-Pacific 2014], article 69411292014, 2014

[12] J. Zhang, M. Wu, "Comparison of numerical methods for nodal analysis in electric railway traction network", Transactions of China Electrotechnical Society, vol. 31, iss. 15, pp. 109-116, 2016.

[13] E. A. Spiridonov, M. V. Yaroslavtsev, "Evaluation of energy recuperation efficiency for operating conditions of city electric transport", Proc. 11 International forum on strategic technology (IFOST 2016) [Novosibirsk State Technical University, Novosibirsk, 2016], Pt. 2, pp. 61-64, 2016.

[14] V. N. Anosov, M. V. Yaroslavtsev, "Increasing the efficiency of a traction electric drive for operation of a trolleybus", Russian Electrical Engineering, iss. 12, vol. 85, pp. 721-723, 2014. 